Johannes Katsarov

DOI: 10.18290/pepsi-2019-0003

Anouk J. Albien

Lea Ferrari*

\title{
Developing a Moral Sensitivity Measure for Career Guidance and Counselling
}

\section{ABSTRACT}

Moral sensitivity, the ability to recognize ethical issues when they arise in practice, is a key premise for career practitioners' professional conduct of Career Guidance Counselling (CGC). Due to the diversity of ethical issues related to CGC and the situational contingency of ethical problems, the assessment of moral sensitivity is challenging. The purpose of this article is to develop a novel measure of moral sensitivity, consisting of triad judgment tasks, to assess whether career practitioners are capable of identifying ten ethical issues related to the CGC practice. In this article, we present our theoretical approach, the development phases of the Guidance Ethical Sensitivity Test (GUEST) and the first administration of the GUEST. The reliability was assessed by performing Polychoric Correlations and Categorical Principal Components Analysis (CATCPA). Administrations showed that ethics experts and most groups with ethics training scored significantly higher than others without ethics training. Future GUEST validations and implications for CGC research, training and policy are discussed.

KEYWORDS: Moral sensitivity, awareness, ethical sensitivity, career guidance, career counselling.

* Correspondence regarding the paper should be sent to: Johannes Katsarov, University of Zurich (Switzerland), e-mail: johannes_katsarov@hotmail.de, or Anouk J. Albien, Stellenbosch University (South Africa) \& University of Bern (Switzerland), e-mail: anouka@sun.ac.za, or Lea Ferrari, University of Padua (Italy), e-mail: lea.ferrari@unipd.it 
Part of what characterizes the CGC field, is the complexity of practice based on each clients' individual case. Specifically, the relevance of clients' motives and interests, their abilities and talents, their social and financial resources, the expectations of their families and social contexts, the availability of relevant training or jobs now and in the future, etc. This complexity is what necessitates professionalism in career guidance and counselling (Weber \& Katsarov, 2012). Competent career professionals are needed who can personally judge what kind of career support a client requires, by considering a wide range of knowledge on the individual, organizational and societal levels. Additionally, professionals are needed who can customize, continuously reflect and optimize the process of career support to address their clients' needs (Network for Innovation in Career Guidonce and Counselling in Europe [NICE], 2016).

As a result, ethical ${ }^{1}$ concerns are omnipresent in the CGC practice. They present themselves at three levels. At the micro-level, which characterizes the interaction between practitioners and clients, trust is earned by respecting the autonomy, dignity and privacy of clients, and enacted by being honest, fair and compassionate. Caring practitioners should do their best to avoid harm to clients: This necessitates an awareness of their own limitations, needs, values, biases and stereotypes, because these can misinform them about what is in the client's interest. At the organizational level, practi-

1 In this article, we use the terms "ethical" and "moral" interchangeably. We recognize that some authors prefer to distinguish these terms, e.g., by holding that morality refers to people's beliefs of what is right or good, while ethics refers to deliberation about such questions. In any case, the concepts overlap to a large degree, so we wo not endorse a strict distinction. For consistency, the prefix moral is used in this article when speaking of people's abilities (e.g., moral sensitivity) and conduct (e.g., moral behavior). Simultaneously, the prefix ethical is used when a moral concern is applied in a specific domain (i.e., an ethical issue vs. a non-ethical issue), when referring to agreed norms (e.g., ethical standards) or theories (e.g., ethical principles). 
tioners deal with questions of need and justice: Should all clients get an equal amount and quality of support or is it legitimate to afford some clients more attention than to others? At the societal level, the practice is expected to contribute to political goals like social inclusion, a stable economy, the dignity and self-directedness of citizens. These are goals inherently ethical in promoting what is viewed to be right and good. Yet, career professionals may ignore or overlook ethical issues or aspects at times. According to Katsarov and Christen (2018), major contributors to moral ignorance are cognitive overload (e.g., due to stress and the complexity of the situation), psychological biases (e.g., conflicts of interest), and attitudes of moral disengagement (e.g., the moral exclusion of specific population groups from ethical consideration). This implies that in a turbulent world of work, where greater job uncertainty is faced and the integration of diverse population groups is a struggle, moral sensitivity becomes a topic of increasing importance to facilitate career transitions. Dedicated ethics training is needed to develop career professionals' abilities to recognize ethical issues in practice. Moreover, instruments for (self-) assessment are needed to show practitioners how they may lack awareness of ethical issues and demands, which are particularly pertinent in the CGC practice.

\section{CHALLENGE}

Numerous studies have shown how individuals often fail to recognize ethical issues, despite the importance they place on upholding diverse ethical values like justice (Jordan, 2009; Bazerman \& Tenbrunsel, 2011). As a result of this moral ignorance, individuals may unknowingly engage in unethical decision-making and conduct (Blum, 1991). Hence, moral sensitivity has been assigned increasing attention over the past decades. It is the first dimension of ethics training in the Four-Component Model (Rest, 1982), 
in the Integrated Ethical Education approach (Narvaez, 2006) and the Theory of Moral Intelligence (Tanner \& Christen, 2014).

In the CGC field, professional ethical values have been gaining increasing importance alongside the practice's professionalization. Recently, several codes of ethics have been updated at the national and international levels (e.g., CDP 2012, dvb 2016, IAEVG 2017, NCDA 2015). In addition, professional values have been identified as central learning outcomes for the training of career practitioners in the European NICE Curriculum Framework (NICE, 2012, pp. 66-81). However, no validated measure of moral sensitivity has been developed for the CGC practice so far (only for the close fields of psychology and counselling).

During the 1980s, two production-task-based measures for moral sensitivity in counselling were developed and tested by Lindsey (1986) and Volker (1984). Production tasks present scenarios to people followed by open-question interviews about these scenarios. Volker (1984) found no differences in moral sensitivity between novice and experienced counsellors. However, Lindsey (1986) found that experienced counsellors and counsellors pursuing a PhD were significantly more sensitive to moral aspects. While some of these measures are highly refined and validated (e.g., Sirin et al., 2003; You et al., 2011), their application is very time-intensive, subject to inter-rater reliability differences and a focus on few cases and ethical dimensions (Jordan, 2007). In contrast, well-validated item-based measures have faced other critique concerning their external validity and the direct engagement with participants for ethical appraisals, which overlooks social desirability and priming effects. Critics question whether people would recognize ethical issues or be able to provide self-assessments of their moral awareness, without prompting (e.g., Reynolds, 2006). Due to these existing shortcomings in moral sensitivity assessments, our goal is to develop an alternative quantitative measure that overcomes these limitations. 
A more recent, promising approach is provided by Fialkov, Jackson and Rabinowitz (2014) with a novel test of moral sensitivity for psychologists based on triad judgment tasks. Previous research has shown that triad judgment tasks can be used to assess cognitive problem representation in domains like statistics or education (e.g., Rabinowitz \& Hogan, 2008). The underlying idea is that people's competence/expertise in a certain domain becomes apparent in their ability to identify structural similarities among problems, by drawing on large, well-organized networks of concepts (cf. Sternberg, 1998). This means that statistical experts are good at recognizing statistical problems, whereas novices may find it difficult to identify implicit structural similarities.

In triad judgment tasks, people are first presented with a "target vignette." Then, they are asked which of two other vignettes is more similar to the target vignette (example below in Table 2). Fialkov et al. (2014) presented 30 target vignettes to respondents, each of which included (a) a surface-level description and (b) a deep-level ethical dimension. Three different types of triads were presented to respondents (ten each):

(1) pure surface-level matches, where only one of the vignettes matched the target vignette, and did so at the surface level only (e.g., location, groups of people);

(2) pure deep-level matches, where only one of the vignettes matched the target vignette, and did so at the deep-level of a common ethical problem only (e.g., ethical issues related to multiple relationships with clients);

(2) conflicting vignettes, where a distractor vignette matches the target vignette at the surface level only, whereas the correspondent vignette matches the target vignette at the deep-level only (i.e., representation of a common ethical problem).

Fialkov et al.'s (2014) results indicated that most of the questioned students of psychology could make correct matches when there were no conflicts between the vignettes (i.e., when they were either presented with Type 1 or Type 2 triads). However, 
when presented with Type 3 triads, respondents with prior ethics training were at a clear advantage (Cohen's $d=1.66)$ : They identified significantly more of the vignettes with common deep-level features (i.e., a common ethical dimension). These results seem to indicate that without a surface-level distractor, most respondents can identify common ethical problems when deciding between a good match and no match at all. However, morally sensitive people are better able to identify common moral issues between two vignettes when distracted by a surface-level similarity of a third vignette.

An advantage of the triad-judgment-task approach lies in the broad representation of ethical problems. Fialkov et al. (2014) were able to address ten ethical issues in their test, each of which reflected a dimension of the APA Ethics Code (APA 2010). A final advantage of the triad-judgment-task approach to assessing moral sensitivity lies in the ease of administration. The presentation of triad judgment tasks does not require people to be present (they can be included in online surveys), nor are they time-intensive for respondents (about one minute per task) or for evaluators (points can be calculated automatically, as no interpretation is required).

In light of the advantages of triad-judgment tasks for the measurement of moral sensitivity and the significant findings of Fialkov et al. (2014), we devoted our efforts to creating a new measure which is able to assess CGC students' and practitioners' awareness for most relevant professional ethical problems: The Guidance Ethical Sensitivity Test (GUEST).

RESEARCH METHODOLOGY

From October 2018 to January 2019 we undertook a first study to validate the GUEST, after we had developed the measure beginning in early 2018. 


\section{Hypotheses and Method}

Recent meta-analyses on ethics training show that ethics training generally has positive effects on the development of competences like moral sensitivity (e.g., Medeiros et al., 2017). This allows us to hypothesize that participants with more ethics training ought to achieve higher test scores compared to those with less ethics training $\left(\mathrm{H}_{1}\right)$. However, studies have also found that the sole provision of ethics training does not predict equal outcomes (e.g., Chan \& Leung, 2006). For instance, ethics courses with active participation of learners are known to be more effective than courses, where learners are passive (Medeiros et al., 2017). Therefore, we hypothesized that ethics training is not a uniformly good predictor of performance on the GUEST $\left(\mathrm{H}_{2}\right)$. For this reason, we decided to compare several courses and a group of ethics experts, expecting that the ethics experts and participants of a highly interactive ethics course specifically for career practitioners would yield the highest scores on average.

Lastly, we wanted to test the frequent assumption that respondents should not be aware that their moral/ethical sensitivity is being assessed in order to prevent socially desirable cognitions and behaviours (e.g., Reynolds, 2006). Obfuscating the purpose of moral sensitivity tests to respondents poses great restrictions on the use of such tests, so it would be preferable to work with tests that are not prone to socially desirable behaviour. Hence, we randomly assigned respondents to a Control Group (CG) and an Informed Group (IG). On three occasions, the members of the CG were informed that the test was about "pattern recognition" whereas the IG members were informed that they were performing a test of "moral sensitivity." We hypothesised that no differences would be found between the CG and the IG, since the GUEST is not an attitudinal measure, but a measure of competence $\left(\mathrm{H}_{3}\right)$. 


\section{Participants}

In this study, we had a total of 83 participants $(M=26.5$ years old, $S D=6.3)$, representing five different sub-groups that we aimed to include (see Table 1 below). We wanted students with ethics (E) and without ethics (WE) training to compare GUEST scores. We tested Italian students, of whom 17 attended psychology courses (E: 11; WE: 6), 40 students enrolled in teacher training (E: 6; WE: 34) and 13 students from other courses with no ethics training (business, medicine, etc.). We also included a group of Scottish postgraduate CGC students (career practitioners) with intensive ethics training $(n=8)$ and a group of ethics experts $(n=5)$ to compare GUEST scoring patterns. We used a random allocation process to assign students to two groups: CG $(n=43)$ and to the IG $(n=40)$ where the assessment of moral sensitivity (i.e., their "ability to recognize ethical issues") was made explicit.

Table 1. Respondent Characteristics.

\begin{tabular}{|c|c|c|c|c|}
\hline Group & $N$ & $\mathrm{Age}^{1}$ & Male & $\begin{array}{c}\text { Academic } \\
\text { Level }^{2}\end{array}$ \\
\hline Psychology Students (WE) & 6 & $26.0(5.4)$ & $20 \%$ & 0 \\
\hline Psychology Students (E) & 11 & $24.1(2.6)$ & $0 \%$ & 1 \\
\hline Teaching Students (WE) & 34 & $25.5(4.4)$ & $0 \%$ & 0 \\
\hline Teaching Students (E) & 6 & $23.3(0.5)$ & $33 \%$ & 0 \\
\hline Other Students (WE) & 13 & $22.4(1.4)$ & $80 \%$ & 0 \\
\hline CGC Students (E) & 8 & $33.7(7.4)$ & $14 \%$ & 1 \\
\hline Ethics Experts (E) & 5 & $39.4(9.4)$ & $40 \%$ & 2 \\
\hline All & 83 & $26.5(6.3)$ & $22 \%$ & 0 \\
\hline
\end{tabular}

${ }^{1}$ Age $=$ Average age (standard deviation).

${ }^{2}$ Academic Level (Median): 0 = no degree, $1=$ BA degree, $2=$ MA degree, $3=\mathrm{PhD}$.

\section{Measure - The Guidance Ethical Sensitivity Test (GUEST)}

The GUEST consists of ten triad-judgment-task vignettes. In triad judgment tasks, people are presented with a target vignette and 
two other vignettes. Their task is to select the vignette, which is most similar to the target vignette. This approach will allow for the test to take only a couple of minutes, which makes it useful for many purposes. In all of our triads, a deep-level ethical-issue match conflicts with a surface-level distractor match. Identifying the common ethical issue when distracted by a surface-level similarity is where moral sensitivity becomes apparent. One example of a triad from the GUEST is provided in Table 2. Using two steps, we assessed students' and practitioners' awareness for ten ethical problems that are central for professionalism and quality in the CGC field and are representative of the diversity of ethical dimensions relevant for our field.

Table 2. Vignette 1 from the GUEST.

\begin{tabular}{|c|c|}
\hline \multicolumn{2}{|c|}{ Target Vignette } \\
\hline $\begin{array}{c}\text { A university counsellor supports a pregnant woman in identifying a suitable } \\
\text { study program and signing up for it, although he personally believes that wom- } \\
\text { en should fully concentrate on childrearing until children visit a kindergarten. }\end{array}$ \\
\hline Which of the following two vignettes is more similar to the target vignette? \\
\hline Vignette A & Vignette B \\
\hline $\begin{array}{c}\text { A university professor reduces her } \\
\text { working hours to take care of one of } \\
\text { her children, who is having problems } \\
\text { at school. }\end{array}$ & $\begin{array}{c}\text { A mother and a father, both athe- } \\
\text { ists, accept that their 15-year old son } \\
\text { wants to attend a religious summer } \\
\text { school with his best friend, and pay } \\
\text { the tuition. }\end{array}$ \\
\hline
\end{tabular}

Note. Vignette A is the distractor vignette, Vignette B is the deep-level correspondent vignette. The relevant ethical issue is paternalism, i.e., subjecting others to one's personal values and preferences in domains, where they should be autonomous.

First, in order to identify one ethical issue per triad judgment task, we compared several ethical standards for career guidance and counselling, including German value-based quality standards (BeQu 2014, CDP 2012, DGfB 2003, DGfK 2007, dvb 2016, IAEVG 2017, NCDA 2015, S\&G 2004). Our original idea was to develop vi- 
gnettes for each of ten ethical values that Katsarov (2018) identified as important in the CGC practice: autonomy, beneficence, care, dignity, equality, justice, non-maleficence, respect for diversity, trust (accountability), and veracity. However, we soon realized that many of these values could relate to several ethical issues. For example, a client's autonomy could be threatened by (1) a practitioner's paternalistic expert attitude ("I know what's good for you"), (2) through coercion ("Either you do as you are told, or we will punish you"), or (3) be strengthened through education or empowerment ("We want you to be able to deal with future career challenges yourself"). Therefore, in the second step, we decided to identify ten common ethical issues of the CGC practice, which cover a wide span of value dimensions. Appendix I provides an overview, description and the associated value dimension of the ten ethical issues.

To ensure that our vignettes are relevant for the purposes of this study, we worked with the following quality criteria in designing the vignettes:

1. Each set of target and correspondent vignettes needs to relate to one ethical issue to avoid confusion and test the accessibility of relevant cognitive categories.

2. Each vignette needs to bear surface-level features through which distraction can be created (e.g., type of professionals involved, type of clients involved, etc.).

3. The vignettes need to correspond in their length (i.e., 20-45 words) and style (i.e., short, concise, descriptive, describing a professional's action/decision).

4. Values and virtues, whether ethical or not, should not be explicitly named in the vignettes, not as adjectives (e.g., fair), nouns (e.g., justice) or verbs (e.g., he cares).

5. Ethical value dimensions are integrated discretely by providing concrete reasons that signify a value dimension (e.g., although, because). 
6. Some distractor vignettes (about $50 \%$ ) should include an ethical dimension other than one in the target vignette. Vignettes should not be solely matched on the mere coverage of ethical content, but on the correspondence of specific ethical issues.

After the creation of the GUEST, expert interviews were undertaken. Seven experts were asked to complete the test while thinking aloud to make their decision-making processes transparent. Thereby any concerns could be identified, such as ambiguous word choices. Word substitutions were made to allow vignettes to be gender neutral and complex terminology was removed to allow ease of understanding.

\section{Procedure}

The GUEST was originally developed in English and then translated into Italian and German, following a back- and forward- translation approach. During this process, we also revised the English vignettes in view of gender equality. It was necessary to specify the gender of agents more frequently in the German and Italian versions than in the English version. In deciding upon the agents' gender (where required), we also took the social status of the agents' roles into account and ensured an equal distribution of male and female agents for high-status (e.g., parent, manager) and low-status (e.g., child, employee) positions. After this process was completed, the GUEST-E/I/G was converted into an online questionnaire using LamaPoll. It was at this point that the GUEST was distributed to the different groups. Participants were assigned to the Control Group (CG) and Informed Group (IG) randomly, but both groups were presented with the same vignettes (in random order). 
RESULTS

\section{Exploratory Factor Analysis (EFA)}

The reliability of the GUEST was assessed by performing an EFA. Due to the categorical/binary scale of the data (i.e., vignette match $=$ correct $/$ incorrect), a normal distribution could not be assumed. Hence, two recommended approaches were used to investigate the factor structure with SPSS (cf. IBM 61077): (1) Categorical Principal Components Analysis (CATCPA), and (2) Exploratory Factor Analysis on the basis of Polychoric Correlations (Heinz 2017).

The findings of both explorations were very similar. In the first step, three factors with Eigenvalues $>1$ emerged once Vignette 7 had been removed due to lack of variance (i.e., the correct match was too obvious). In the second step, two additional vignettes (V5 and V10) were removed: V5 proved to be too difficult (Factor 1 was not loaded) and V10 did not load on any of the three factors, indicating a low reliability. Once only seven vignettes were included in the sample, only two factors with Eigenvalues $>1$ remained. We interpret this two-factor structure as follows, drawing on the presented theory:

- Factor 1: The salience of the communality of the ethical issues between the correctly matched vignettes (ethical similarity).

- Factor 2: The salience of the communality of the surface-level features of the wrongly matched vignettes (distractor).

We assumed that these two factors ought to be negatively correlated to a certain extent: The stronger the distraction, the weaker the perceived ethical similarity (and vice versa). Therefore, we decided to perform oblique factor rotations (OBLIMIN) to support the factor interpretation.

The component loadings presented in Table 3 below offer the best presentation of the assumed two-factor structure. Factor 1 (ethical similarity) is positive for all vignettes. In instances, where Factor 2 (distraction) is strong (V4, V6, and V9), the salience of 
Table 3. Exploratory Factor Analysis (Comparison of Two Methods).

\begin{tabular}{|l|c|c|c|c|c|}
\hline & \multicolumn{2}{|c|}{ CATCPA } & \multicolumn{2}{c|}{$\begin{array}{c}\text { EFA with Polychoric } \\
\text { Correlations }\end{array}$} \\
\hline & $\begin{array}{c}\text { Component Loadings p } \\
\text { er Dimension }\end{array}$ & \multicolumn{2}{c|}{$\begin{array}{c}\text { Component Loadings } \\
\text { per Dimension }\end{array}$} \\
\hline Vignette 1 & 0.634 & -0.198 & & 0.630 & -0.169 \\
\hline Vignette 2 & 0.494 & -0.466 & 0.469 & -0.291 \\
\hline Vignette 3 & 0.674 & -0.171 & 0.701 & -0.170 \\
\hline Vignette 4 & 0.333 & 0.691 & & 0.368 & 0.681 \\
\hline Vignette 6 & 0.373 & 0.432 & & 0.328 & 0.212 \\
\hline Vignette 8 & 0.545 & -0.240 & & 0.493 & -0.174 \\
\hline Vignette 9 & 0.470 & 0.447 & & 0.438 & 0.292 \\
\hline & $\begin{array}{c}\text { Variable principal normaliza- } \\
\text { dion with OBLIMIN rotation }\end{array}$ & & $\begin{array}{c}\text { Principal axis factoring } \\
\text { OBLIMIN }\end{array}$ \\
\hline
\end{tabular}

Table 4. Mean Scores of Seven Groups on Guidance Ethical Sensitivity Test (GUEST).

\begin{tabular}{|l|c|c|c|c|}
\hline Group & Mean & $N$ & $S D$ & T-Test (0.5) \\
\hline Psychology Students (WE) & 0.48 & 6 & 0.22 & $\mathrm{~T}=-.271, p=.797$ \\
\hline Psychology Students (E) & 0.40 & 11 & 0.25 & $\mathrm{~T}=-1.314, p=.218$ \\
\hline Teaching Students (WE) & $0.58^{*}$ & 34 & 0.21 & $\mathrm{~T}=2.343, p=.025$ \\
\hline Teaching Students (E) & $0.74^{*}$ & 6 & 0.21 & $\mathrm{~T}=2.774, p=.039$ \\
\hline Other Students (WE) & 0.53 & 13 & 0.23 & $\mathrm{~T}=.433, p=.673$ \\
\hline CGC Students (E) & $0.82^{* *}$ & 8 & 0.21 & $\mathrm{~T}=4.277, p=.004$ \\
\hline Swiss Ethics Experts (E) & $0.86^{* *}$ & 5 & 0.22 & $\mathrm{~T}=5.590, p=.005$ \\
\hline All & $0.59^{* *}$ & 83 & 0.25 & $\mathrm{~T}=3.475, p=.001$ \\
\hline
\end{tabular}

Average score on seven triad-judgment tasks from (from $0=$ all wrong to $1=$ all correct). ${ }^{*} p<0.05,{ }^{* *} p<0.01,{ }^{* * *} p<0.001$. 
the ethical similarity is reduced, partially leading to lower factor loadings. Especially V4 and V9 were characterized by relatively low levels of correct matches which indicates a high difficulty, whereas V2 was most frequently matched correctly. We interpreted the moderate factor loadings of the first dimension (> .3 and $<.7)$ as acceptable. In cases where participants were uncertain of a vignette match, one of the two vignettes were probably chosen at random. Thus, very high factor loadings would indicate that a triad is too easy (ethical similarity) or difficult (distractor).

\section{Group Comparisons of GUEST Scores}

The GUEST score is calculated as the mean of the single scores of the seven retained triad-judgment tasks. Therefore, the GUEST score can be considered as an interval scale measurement and comparisons of mean values are intelligible. We compared the mean scores of the seven groups who performed the GUEST (see Table 4 above) to investigate $\mathrm{H} 1$ and H2. The Psychology $(\mathrm{n}=17)$ and Teaching students $(\mathrm{n}=40)$ were divided into subgroups, depending on whether they had received ethics training so far. A GUEST Score of 0.5 ought to be achieved on average, if vignettes are randomly chosen. Therefore, T-Tests per group were conducted to assess if GUEST Scores significantly differed from the value of 0.5 . The results suggest the correctness of $\mathrm{H}_{1}$ and $\mathrm{H}_{2}$ :

- $\mathrm{H}_{1}$ : The scores of the ethics experts and most groups with ethics training were significantly higher than 0.5 while the scores of the majority of respondents without ethics training did not significantly deviate from the 0.5 score.

- $\mathrm{H}_{2}$ : In two cases, the groups who had participated in ethics courses scored significantly higher than 0.5 criteria on the test. The Psychology students who had received ethics training did not differ significantly from this mark. 


\section{Regression Analyses}

A series of regressions was performed with the GUEST score as the dependent variable to confirm the preliminary findings on $\mathrm{H}_{1}$ and $\mathrm{H}_{2}$, and to investigate $\mathrm{H}_{3}$ (see Table 4 below). In Model $1, F(7.68)=1.155, p=.340, n=76$, we tested basic independent variables (e.g., the quantity of ethics training people had received). In Model 2, $F(12.63)=3.323, p=.001, n=76$, we added the different categories of ethics courses (e.g., school-based) and distinct codes of ethics, arriving at a significant model, which explains $27.1 \%$ of the variance. In Model 3, $F(9.66)=3.363, p=.002, n=76$, we focused on the effectiveness of distinct ethics courses, explaining $22.1 \%$ of the variance. To arrive at Model $4, F(8.70)=6.118$, $p=.000, n=79$, we used a STEPWISE procedure (i.e., adding and removing independent variables) until we found the model with the highest corrected $R^{2}$, explaining $34.4 \%$ of the variance.

- Examining $\mathrm{H}_{1}$ : Models 2 and 4 clearly demonstrate that people with ethics training performed significantly better on the test on average, confirming $\mathrm{H}_{1}$.

- Examining $\mathrm{H}_{2}$ : Model 1 shows that the quantity of ethics training alone could not account for variance in test scores. Models 2, 3 and 4 show that some ethics courses seemed to have had negative effects on the development of moral sensitivity (e.g., an ethics course offered to a sample of Psychology students). Yet other ethics courses yielded positive effects (e.g., a CGC ethics course). These findings confirm $\mathrm{H}_{2}$.

- Examining $\mathrm{H}_{3}$ : Whether respondents were aware of the test being about their moral sensitivity or not, did not make a significant difference. This confirms $\mathrm{H}_{3}$. 
Table 5. OLS-Regressions for GUEST Score.

\begin{tabular}{|c|c|c|c|c|}
\hline $\begin{array}{c}\text { Independent } \\
\text { Variable }\end{array}$ & Model 1 & Model 2 & Model 3 & Model 4 \\
\hline Ethics Priming ${ }^{1}$ & $.043(.058)$ & $.033(.053)$ & $.069(.052)$ & $.060(.048)$ \\
\hline $\mathrm{Age}^{2}$ & $-.010(.064)$ & $-.091(.061)$ & $-.110(.062)$ & $-.095(.051)$ \\
\hline Gender $^{3}$ & $-.007(.070)$ & $-.058(.062)$ & $.021(.063)$ & \\
\hline CGC Practice $^{4}$ & $.079(.043)$ & $-.008(.045)$ & $.015(.044)$ & \\
\hline Academic Level $^{5}$ & $.042(.051)$ & $.082(.049)$ & $.035(.055)$ & \\
\hline $\begin{array}{l}\text { Quantity/ethics } \\
\text { training }^{6}\end{array}$ & $.026(.029)$ & $.089 *(.036)$ & & $.045^{*}(.021)$ \\
\hline School-based $^{1}$ & & $-.200 *(.080)$ & & $-.074(.056)$ \\
\hline Another provider ${ }^{1}$ & & $\begin{array}{c}-.417^{* * *} \\
(.111)\end{array}$ & & $-.214^{* *}(.076)$ \\
\hline University-based $^{1}$ & & $-.066(.095)$ & & \\
\hline Psych. ethics $^{1}$ & & & $-.184 *(.086)$ & \\
\hline Teacher ethics $^{1}$ & & & $.166(.095)$ & $.110(.087)$ \\
\hline CGC ethics $^{1}$ & & & $.321^{* *}(.116)$ & $.325^{* *}(.089)$ \\
\hline Ethics experts ${ }^{1}$ & & & $.396^{*}(.155)$ & $.469^{* * *}(.123)$ \\
\hline Ethics codes studied $^{7}$ & $-.065(.056)$ & & & \\
\hline CGC $\operatorname{code}^{1}$ & & $.210(.127)$ & & \\
\hline Psychological code $^{1}$ & & $-.297^{* *}(.085)$ & & $-.202^{* *}(.064)$ \\
\hline Educational code $^{1}$ & & $-.020(.078)$ & & \\
\hline Intercept & $.578 * *(.198)$ & $.898^{* * *}(.190)$ & $.685^{* * *}(.178)$ & $.773^{* * *}(.145)$ \\
\hline $\begin{array}{l}N \\
R^{2}(\text { corrected })\end{array}$ & $\begin{array}{c}76 \\
.014\end{array}$ & $\begin{array}{c}76 \\
.271\end{array}$ & $\begin{array}{l}76 \\
.221\end{array}$ & $\begin{array}{c}79 \\
.344\end{array}$ \\
\hline
\end{tabular}

Note. Standard errors in parentheses, statistically significant findings in bold.

${ }^{*} p<0.05,{ }^{* *} p<0.01,{ }^{* * *} p<0.001$.

${ }^{1}$ Categories: 1 = No, 2 = Yes; ${ }^{2}$ In decades $;{ }^{3}$ Categories: 1 = Male, $2=$ Female; ${ }^{4}$ Categories:

$0=$ None $/ 3=$ More than 10 years; ${ }^{5}$ Categories: $0=$ No degree $/ 3=\mathrm{PhD} ;{ }^{6}$ Categories:

$0=$ None $/ 4=>60 \mathrm{~h} ;{ }^{7}$ Number: 0 to 2 courses. 
LIMITATIONS, RECOMMENDATIONS \& CONCLUSIONS

The current research presents an innovative approach to assessing moral sensitivity in the CGC domain. The vignettes appear promising in identifying students and practitioners that need to increase their moral sensitivity and could be used to plan future learning activities. As in other research on ethics training, many factors such as duration and contents appear to have an impact on the development of moral sensitivity. Further studies are necessary to clarify the characteristics that could help to maximize the success of these trainings. Knowledge about the test's purpose (ethics priming) does not seem to improve the ability to identify deep-level vignettes and suggests that in the next phases of validating the GUEST, the test's purpose can be made explicit.

Although the GUEST proves promising, there are limitations that future research needs to address. First, we worked with relatively small convenience samples, especially for some of the groups. Therefore, the results need to be interpreted with caution and no general inferences should be made, e.g., about psychology students or ethics experts in general. In the near future, we will conduct a second validation study using larger samples. We are already planning to conduct relevant surveys in Italy, Germany, South Africa and Switzerland, but colleagues from other countries are also invited to participate. In preparation of this study, we will improve the three vignettes that were not reliable in this study.

Finally, we would like to thank all the participants who took part in this research process. Furthermore, we would like to thank Carmen Tanner for her statistical advice on the exploratory factor analysis and Rosie Alexander, Emma Bolger, Gideon De Bruin, Sonya Katsarova, Siobhan Neary, Marietha de Wet, and Paul $\mathrm{J}$. Hartung for their support in developing the vignettes. 


\section{REFERENCES}

Bazerman, M., \& Tenbrunsel, A. (2011). Blind spots: Why we fail to do what's right and what to do about it. Princeton: Princeton University Press.

BeQu (2014). Professionell beraten: Qualitätsstandards für die Beratung in Bildung, Beruf und Beschäftigung. Berlin: W. Bertelsmann.

CDP (2012). Code de déontologie des psychologues [Code of Ethics for Psychologists]. Retrieved February 15, 2018, from http://www.codededeontologiedespsychologues.fr/LE-CODE.html

Chan, S., \& Leung, F. (2006). The effects of accounting students' ethical reasoning and personal factors on their ethical sensitivity. Managerial Auditing Journal, 21(4), 436-457. DOI:10.1108/02686900610661432.

DGfB (2003). Beratungsverständnis. Köln: Deutsche Gesellschaft für Beratung e.V. Retrieved February 15, 2018, from http://dachverband-beratung.de/ dokumente/DGfB_Beratungsverstaendnis.pdf

DGfK (2007). DGfK Standards und ethische Grundsätze. Deutsche Gesellschaft für Karriereberatung e.V. Retrieved February 15, 2018, from http:/ /www.dgfk. org/ethische-grundlagen.html

dvb (2016). Professionelle Bildungs- und Berufsberatung [Professional Career Guidance]. Deutscher Verband für Bildungs- und Berufsberatung e.V. Retrieved February 2, 2018, from http:/ / www.dvb-fachverband.de/fileadmin/medien/grundsatzpapiere_dvb/2016_04_23_Grundlagenpapier.pdf

Fialkov, E. D., Jackson, M. A., \& Rabinowitz, M. (2014). Effects of experience and surface-level distraction on ability to perceive ethical issues. Training and Education in Professional Psychology, 8(4), 277-284. http://dx.doi.org/10.1037/ tep0000067

Heinz, S. (2017). Faktorenanalyse mit binären Items in SPSS. Blog post from August 28, 2017. Retrieved March 22, 2019, from https://www.statworx. $\mathrm{com} / \mathrm{at} / \mathrm{blog} /$ faktorenanalyse-mit-binaeren-items-in-spss/

IAEVG (2017). IAEVG Ethical Guidelines. Mexico City: International Association for Education and Vocational Guidance. Retrieved August 13, 2018, from http://iaevg.net/wp-content/uploads/IAEVG-EthicsNAFeb2018Final.pdf IBM (61077). Exploratory Factor Analysis with categorical variables. IBM Support no. 61077. Retrieved March 22, 2019, from https:/ /www-01.ibm.com/ support/docview.wss?uid=swg21477550

Jordan, J. (2007). Taking the first step toward a moral action: a review of moral sensitivity measurement across domains. The Journal of Genetic Psychology, 168(3), 323-359. http://dx.doi.org/10.3200/GNTP.168.3.323-360 
Jordan, J. (2009). A social cognition framework for examining moral awareness in managers and academics. Journal of Business Ethics, 84, 237-258. DOI: 10.1007/s10551-008-9706-3

Katsarov, J. (2018, February). Internationale und nationale Ethikstandards für die Beratung - Was wollen wir damit? Kick-off speech (Forum 2) at the conference "Ethik in der Beratung" at the University of Applied Labor Studies in Mannheim. Retrieved March 29, 2019, from https:/ /www.dvb-fachverband. de/fileadmin/user_upload/Katsarov_2018_Ethik_in_der_Beratung_korr.pdf

Katsarov, J., \& Christen, M. (2018). Promoting the moral sensitivity of policy and military personnel. NECESSE, 3(1), 114-120.

Lindsey, R. T. (1986). Differences in moral sensitivity based on varying levels of counseling training and experience (Unpublished doctoral dissertation). Denver: University of Denver.

Medeiros, K., Watts, L., Mulhearn, T., Steele, L., Mumford, M., \& Connelly, S. (2017). What is working, what is not, and what we need to know: A metaanalytic review of business ethics instruction. Journal of Academic Ethics 15: 245-275. DOI: 10.1007/s10805-017-9281-2

Narvaez, D. (2006). Integrative ethical education. In M. Killen \& J. Smetana (Eds.), Handbook of Moral Development (pp. 703-733). Mahwah, NJ: Erlbaum. NCDA. (2015). 2015 NCDA code of ethics. Broken Arrow, OK: National Career Development Association. Retrieved February 15, 2018, from https:/ /www. ncda.org/aws/NCDA/asset_manager/get_file/3395

NICE. (2012). NICE handbook for the academic training of career guidance and counselling professionals (edited by C. Schiersmann, B.-J. Ertelt, J. Katsarov, R. Mulvey, H. Reid, \& P. Weber). Heidelberg: Heidelberg University.

NICE. (2016). European Competence Standards for the Academic Training of Career Practitioners. NICE Handbook Volume II (edited by C. Schiersmann, S. Einarsdóttir, J. Katsarov, J. Lerkkanen, J. Pouyaud, K. Pukelis, R. Mulvey, \& P. Weber). Opladen: Barbara Budrich.

Rabinowitz, M., \& Hogan, T. (2008). Experience and problem representation in statistics. American Journal of Psychology, 121, 395-407. DOI:10.2307/20445474

Rest, J. (1982). A psychologist looks at the teaching of ethics. Hastings Center Report, 12(1), 29-36.

Reynolds, S. J. (2006). Moral awareness and ethical predispositions: Investigating the role of individual differences in the recognition of moral issues. Journal of Applied Psychology, 91, 233-243. DOI: 10.1037/0021-9010.91.1.233

S\&G (2004). Code of Ethics. The Canadian Standards \& Guidelines for Career Development Practitioners. Retrieved February 15, 2018, from http:/ / career- 
dev-guidelines.org/career_dev/index.php/the-standards-guidelines / code-of-ethics

Sirin, S. R., Brabeck, M. M., Satiani, A., \& Rogers-Serin, L. (2003). Validation of a measure of moral sensitivity and examination of the effects of previous multicultural and ethics courses on moral sensitivity. Ethics $\mathcal{E}$ Behavior, 13(3), 221-235.

Sternberg, R. (1998). Abilities are forms of developing expertise. Educational Researcher, 27(3), 11-20.

Tanner, C., \& Christen, M. (2014). Moral intelligence - a framework for understanding moral competences. In M. Christen, J. Fischer, M. Huppenbauer, C. Tanner, \& C. van Schaik (Eds.), Empirically Informed Ethics (pp. 119-136). Berlin: Springer.

Volker, J. M. (1984). Counseling experience, moral judgment, awareness of consequences and moral sensitivity in counseling practice. Dissertation Abstracts International, 45(3-A), 793-794. (UMI No. 19850301)

You, D., Maeda, Y., \& Bebeau, M. J. (2011). Gender differences in moral sensitivity: a meta-analysis. Ethics \& Behavior, 21, 263-282. DOI: 10.1080/ 10508422.2011.585591

Weber, P., \& Katsarov, J. (2012). Benefits of professionalizing career guidance and counselling. In NICE, NICE Handbook for the Academic Training of Career Guidance and Counselling Professionals (pp. 15-26). Heidelberg: Heidelberg University.

\section{APPENDIX I: OVERVIEW OF ETHICAL ISSUES AND VALUE DIMENSIONS}

\begin{tabular}{|l|l|l|}
\hline \multicolumn{1}{|c|}{ Issue } & \multicolumn{1}{|c|}{ Description } & \multicolumn{1}{c|}{ Values } \\
\hline 1) Paternalism & $\begin{array}{l}\text { Respecting and promoting clients' } \\
\text { autonomy to make their own decisions, } \\
\text { based on their own goals and values. }\end{array}$ & $\begin{array}{l}\text { Tolerance/ } \\
\text { Diversity/ } \\
\text { Autonomy }\end{array}$ \\
\hline 2) Coercion & $\begin{array}{l}\text { Refraining from the use of power } \\
\text { (authority, sanctions, group pressure, etc.) } \\
\text { in enforcing exterior (non-client) goals } \\
\text { and values on clients' decision-making } \\
\text { and career development. }\end{array}$ & $\begin{array}{l}\text { Liberty/ } \\
\text { Autonomy }\end{array}$ \\
\hline
\end{tabular}




\begin{tabular}{|c|c|c|}
\hline Issue & Description & Values \\
\hline 3) Abandonment & $\begin{array}{l}\text { Taking care of clients and helping them } \\
\text { to stand up for themselves when they } \\
\text { need assistance, e.g., in facing strong } \\
\text { opposition. }\end{array}$ & Care \\
\hline 5) Discrimination & $\begin{array}{l}\text { Providing equally good support for } \\
\text { clients, independent of their ability, age, } \\
\text { attractiveness, beliefs, culture, ethnicity, } \\
\text { gender, marital/partnership status, sexual } \\
\text { orientation, socioeconomic status, or } \\
\text { any other characteristics not specifically } \\
\text { relevant for reaching the clients' goals. }\end{array}$ & Equality \\
\hline 6) Advocacy & \begin{tabular}{|l|} 
Promoting social justice at the levels of \\
organizations and institutions to ensure \\
equal access to career support and \\
equitable opportunities for educational \\
and vocational development and \\
inclusion for all citizens.
\end{tabular} & Social Justice \\
\hline $\begin{array}{l}\text { 7) Competence / } \\
\text { Limitations }\end{array}$ & $\begin{array}{l}\text { Being aware of one's own limitations } \\
\text { and taking steps to protect clients from } \\
\text { the consequences of one's own possible } \\
\text { mistakes. }\end{array}$ & Non-Maleficence \\
\hline 8) Transparency & $\begin{array}{l}\text { Offering clients an accurate depiction of } \\
\text { one's services, qualification, approach } \\
\text { and methods, and knowledge. }\end{array}$ & Honesty \\
\hline $\begin{array}{l}\text { 9) Privacy / } \\
\text { Informed Consent }\end{array}$ & $\begin{array}{l}\text { Protecting clients' personal data from } \\
\text { potential abuse; ensuring that clients } \\
\text { know about their rights, understand the } \\
\text { guidance process and understand with } \\
\text { whom their information must be shared, } \\
\text { if applicable. } \\
\end{array}$ & Trust \\
\hline $\begin{array}{l}\text { 10) Conflicts of } \\
\text { Interest }\end{array}$ & $\begin{array}{l}\text { Avoiding and addressing situations, in } \\
\text { which multiple loyalties may conflict with } \\
\text { each other to prevent situations where } \\
\text { clients may receive biased information } \\
\text { and advice to their disadvantage. }\end{array}$ & Beneficence \\
\hline
\end{tabular}

